\title{
ROLE OF HYSTEROSCOPY IN DIAGNOSING INTRAUTERINE PATHOLOGY
}

\author{
Abinaya Sankaran ${ }^{1}$, Hiremath P. B ${ }^{2}$, Urmi Sanyal ${ }^{3}$ \\ ${ }_{1}^{1}$ Final Year Postgraduate Resident, Department of Obstetrics and Gynaecology, Sri Venkateshwaraa Medical College Hospital \& RC, \\ Ariyur, Pondicherry. \\ 2Professor and HOD, Department of Obstetrics and Gynaecology, Sri Venkateshwaraa Medical College Hospital \& RC, Ariyur, \\ Pondicherry. \\ ${ }^{3}$ Assistant Professor, Department of Obstetrics and Gynaecology, Sri Venkateshwaraa Medical College Hospital \& RC, Ariyur, \\ Pondicherry.
}

\begin{tabular}{l}
\hline ABSTRACT \\
\hline BACKGROUND \\
Hysteroscopy is evolving as a promising imaging modality in the diagnosis of intrauterine pathologies associated with abnormal \\
uterine bleeding due to its non-invasive nature and employability as a screening technique in diagnosing early endometrial \\
neoplastic changes. \\
Aim- To find out the role of hysteroscopy in diagnosing intrauterine pathology in patients with abnormal uterine bleeding. \\
Objectives- To determine and evaluate efficacy of intrauterine pathology associated with abnormal uterine bleeding among pre- \\
menopausal and post-menopausal women by hysteroscopy and to compare with histopathology.
\end{tabular}

\section{MATERIALS AND METHODS}

A hospital-based, descriptive study was conducted at Sri Venkateshwaraa Medical College, Hospital \& Research Centre, Ariyur, Puducherry, among women with abnormal uterine bleeding attending Gynaecological Outpatient Department between October 2015 and July 2017. Patients included for the study were examined clinically after careful history taking and then routine blood investigations were done. After ruling out pregnancy, they were asked to come on day 7 to day 10 of menstrual cycle for hysteroscopy which was done under sedation. Later an endometrial sampling was done.

\section{RESULTS}

The study participants $(\mathrm{N}=60)$ were mostly middle aged people (mean age $=36.85 \pm 5.6$ years) with majority in the $31-40$ years age group. Most of the study subjects were literates (68.3\%), married women (73.3\%) belonging to the upper socioeconomic class (66.7\%). Menorrhagia (40\%) followed by dysmenorrhoea (25\%) and polymenorrhoea (18\%) were the common symptoms complained by the patients. Majority of the AUB cases included in the study were detected to be normal endometrium (35\%) followed by endometrial polyp (31.7\%) and submucous myoma (30\%). There was good concordance in diagnosis between hysteroscopy and histological verification.

\section{CONCLUSION}

The study established that hysteroscopy can be used as a reliable diagnostic method in evaluation of patients with abnormal uterine bleeding.

\section{KEYWORDS}

Abnormal Uterine Bleeding, Hysteroscopy, Histopathology.

HOW TO CITE THIS ARTICLE: Sankaran A, Hiremath PB, Sanyal U. Role of hysteroscopy in diagnosing intrauterine pathology. J. Evolution Med. Dent. Sci. 2017;6(88):6137-6142, DOI: 10.14260/jemds/2017/1333

\section{BACKGROUND}

Abnormal Uterine Bleeding[1] (AUB) is a very common complaint among women belonging to all age groups in any gynaecology clinic.[2] This is further brought into vision by the number of hysterectomies $(75,000 /$ year) done across the country out of which $30 \%$ are due to menstrual irregularities.[3] There are various diagnostic modalities for evaluation of the endometrial or myometrial pathologies, which include the dilatation and curettage (D\&C); office

'Financial or Other Competing Interest': None.

Submission 11-09-2017, Peer Review 23-10-2017,

Acceptance 28-10-2017, Published 06-11-2017.

Corresponding Author:

Dr. Urmi Sanyal,

Assistant Professor,

Department of Obstetrics and Gynaecology,

Sri Venkateshwaraa Medical College Hospital \& RC,

Ariyur, Pondicherry.

E-mail: abinayanarayanan19@gmail.com

DOI: $10.14260 /$ jemds $/ 2017 / 1333$ based endometrial biopsy, abdominal and pelvic ultrasonography and transvaginal ultrasonography. The sensitivity and specificity of these abovementioned techniques in detecting the causative factors for AUB have been evaluated in various studies.[3,4,5] Hysteroscopy and its directed biopsy improve the accuracy than dilatation and curettage, hence it is considered as 'gold standard' in uterine cavity evaluation. ${ }^{[6]}$ Unlike dilation and curettage which lacks specificity, hysteroscopy is more specific and sensitive. The reason is that the entire uterine cavity, pathological site are visualised and from which biopsy taken under direct visual inspection. [7] There is a high incidence of intrauterine lesions $(52 \%)$ in the population presenting with abnormal uterine bleeding (AUB). ${ }^{[8]}$ The present study was designed to know the efficiency of hysteroscopy in evaluation of abnormal uterine bleeding among the patients with AUB. The diagnosis made by hysteroscopy will be evaluated histopathologically. 


\section{Aims \& Objectives}

To determine the intrauterine pathology associated abnormal uterine bleeding among pre-menopausal and postmenopausal women by hysteroscopy.

To evaluate the efficacy of hysteroscopy in correctly diagnosing the intrauterine pathology associated abnormal uterine bleeding among pre-menopausal and postmenopausal women when compared with histopathology.

\section{MATERIALS AND METHODS \\ Type of Study}

Descriptive, hospital-based study.

\section{Study Area}

Sri Venkateshwaraa Medical College, Hospital \& Research Centre, Ariyur, Puducherry.

\section{Study Period}

October 2015 to July 2017.

\section{Study Population}

Women with abnormal uterine bleeding attending Gynaecological Outpatient Department at Sri Venkateshwaraa Medical College Hospital.

\section{Sample Size}

The study units encountered during the study period who fit into the inclusion criteria were all included in the study and the final sampe size was 60 .

\section{Inclusion Criteria}

All women attending Gynaecological Outpatient Department at Sri Venkateshwaraa Medical College, Hospital \& Research Centre, Ariyur, Puducherry with Menorrhagia, Metrorrhagia, Menometrorrhagia, Polymenorrhoea, Polymenorrhagia. Oligomenorrhoea, Dysmenorrhea.

\section{Exclusion Criteria}

Pregnancy, IUCD (Intrauterine contraceptive devices), Hormone producing Ovarian tumours in USG, Hypothyroidism \& Hyperthyroidism, Diabetes, Adrenal disease, prolactin disorders, Coagulation disorders, liver/renal diseases, Known Cervical or uterine malignancy, on medications like steroids, neuroleptics, anticoagulants and cytotoxic agents, recent uterine perforation.

\section{Materials}

Rigid Hysteroscope, light source, uterine distension medium and video camera system.

\section{Method}

After taking a detailed history, physical examination, patient will be investigated to rule out organic causes of AUB with CBC, RFT, LFT, Blood grouping and Rh typing, coagulation profile, thyroid function tests and UPT to rule out pregnancy and USG. After getting informed written consent for the procedure, diagnostic hysteroscopy will be performed.

\section{Pre-Procedure}

Patient will be called on D7-D10 of her menstrual cycle (early proliferative phase). Patient will be kept nil orally for 6 hours before procedure.

\section{Procedure}

Under anaesthesia, patient is placed in dorsal lithotomy position, Perineum and vagina painted with povidone iodine. Posterior vagina is depressed with Sims speculum. The anterior lip of the cervix is grasped with a vulsellum. A suitable telescope is selected and checked for clarity of the eye-piece and objective lens. The telescope is inserted into the diagnostic sheath and the selected medium- Normal saline is flushed through the sheath to expel any air within the sheath.

Karl Stortz Hysteroscope (Endoscope) is used for study. The hysteroscope is inserted into the cervical canal and advanced into the uterine cavity through internal or under direct vision by manipulating along the axis of the canal. Endometrial cavity will be visualised systematically. Any intrauterine pathology is looked for and endometrial sampling will be taken from the abnormal sites for Histopathological examination. Fluid input and output will be monitored to avoid overload.

\section{Post-Procedure}

Patient's general condition, vitals will be checked. Any bleeding per vaginum will be watched for.

\section{RESULTS}

A total of 60 women who came with complaints of alteration in menstrual bleeding patterns/cycles and lower abdominal pain to the Gynaecology OPD at the Department of Obstetrics and Gynaecology, Sri Venkateshwaraa Medical College Hospital and Research Centre, Puducherry during the study period were selected and included for the study as per the inclusion criteria. The study participants were mostly middle aged people (mean age $=36.85 \pm 5.6$ years) with majority in the 31-40 years age group.

Majority of the study participants were around 40 years of age along the peri-menopausal age group. Post-menopausal women represented very less among the studied individuals.

\begin{tabular}{|c|c|c|}
\hline Age Groups (Years) & Frequency & Percentage \\
\hline $20-30$ years & 9 & $15 \%$ \\
\hline $31-40$ years & 39 & $65 \%$ \\
\hline 41-50 years & 12 & $20 \%$ \\
\hline \multicolumn{2}{|c|}{ Table 1. Age Distribution of the Study Participants } \\
\hline
\end{tabular}

Chi-square for trends: $\chi^{2}$ value $=40.95, \mathrm{df}=2, \mathrm{p}$ value $<0.001$, highly significant.

There was a significant difference in the age distribution of the study participants with more participants belonging to the 31-40 years compared to the other two groups. Perimenopausal age group formed majority (65\%) of participants in the study followed by post-menopausal (20\%) and middleaged women (15\%). [Table 1].

Most of the study subjects were literates (68.3\%) who were able to respond to the questions and possess valid opinion and understanding about the procedure done. Illiterates were $31.7 \%$. 


\begin{tabular}{|c|c|c|}
\hline $\begin{array}{c}\text { Socioeconomic } \\
\text { Status }\end{array}$ & Frequency & Percentage \\
\hline Upper class & 21 & $35 \%$ \\
\hline Upper middle class & 19 & $31.7 \%$ \\
\hline Middle class & 8 & $13.3 \%$ \\
\hline Lower middle class & 12 & $20 \%$ \\
\hline Lower class & 0 & 0 \\
\hline
\end{tabular}

Majority of the subjects belonged to the upper class $(66.7 \%)$ which reflects on the co-operation rendered for the investigations and operative procedures along with followup in the hospital. There were no participants in the lowermost class because many opted out from investigations and procedures due to inability to meet expenditures in a private medical college and got referral to government institutions.

Majority of the illiterates belonged to the middle and lower class whereas most of the participants in the upper socioeconomic status were literates as shown in the following diagram.

Majority of study participants are married women $(73.3 \%)$ as compared to single $(26.7 \%)$. The symptoms associated with AUB show significant differences in occurrence among the married and unmarried women.

\begin{tabular}{|c|c|c|}
\hline Symptoms & Frequency & Percentage \\
\hline Menorrhagia & 24 & $40.0 \%$ \\
\hline Polymenorrhoea & 11 & $18.3 \%$ \\
\hline Post-coital bleed & 4 & $6.7 \%$ \\
\hline Metrorrhagia & 6 & $10.0 \%$ \\
\hline Lower abdominal pain & 15 & $25.0 \%$ \\
\hline \multicolumn{2}{|c|}{ Table 3. Symptoms Associated with AUB } \\
\hline
\end{tabular}

\begin{tabular}{|c|c|c|c|}
\hline & $\begin{array}{c}\text { Pre- } \\
\text { Menopausal }\end{array}$ & $\begin{array}{c}\text { Post- } \\
\text { Menopausal }\end{array}$ & Total \\
\hline Regular bleeding & $31(63.3)^{*}$ & $7(63.6)^{*}$ & $38(63.3)^{*}$ \\
\hline $\begin{array}{c}\text { Irregular } \\
\text { bleeding }\end{array}$ & $18(36.7)^{*}$ & $4(36.4)^{*}$ & $22(36.7)^{*}$ \\
\hline Total & $\mathbf{4 9 ( 8 1 . 7 ) ^ { * * }}$ & $\mathbf{1 1 ( 1 8 . 3 ) ^ { * * }}$ & $\mathbf{6 0 ( 1 0 0 )}$ \\
\hline
\end{tabular}

Table 4. Differences in Bleeding Pattern among Pre-and Post-menopausal AUB

Figures in ( $)^{*}$ indicate column percentage $\%$ and ()$^{* *}$ indicate row percentage $\%$.
The pattern of bleeding (regular/irregular) was not significantly different among the pre-menopausal and postmenopausal women.

The regularity in bleeding pattern does not differ much with menopausal status. The incidence of regular bleeding pattern in post-menopausal women questions the very fact of menopause. But all the post-menopausal patients were confirmed of absence of menstrual cycle for a considerable period before onset of abnormal bleeding by history.

\begin{tabular}{|c|c|c|}
\hline & Frequency & Percentage \\
\hline Normal Endometrium & 21 & 35.0 \\
\hline Endometrial polyp & 19 & 31.7 \\
\hline Submucous myoma & 18 & 30.0 \\
\hline Endometrial atrophy & 2 & 3.3 \\
\hline Endometrial carcinoma & 0 & 0 \\
\hline
\end{tabular}

Table 5. Endometrial Type as Detected by Sonogram

Majority of the AUB cases included in the study were detected to be normal endometrium (35\%) followed by endometrial polyp (31.7\%) and submucous myoma (30\%). Those who underwent sonogram were examined by hysteroscopy and the concordance of findings was evaluated.

\section{Hysteroscopy and Sonography}

The comparison of sonography and hysteroscopy findings about the endometrium reveals the advantage of hysteroscopy which is a direct visualisation over sonogram which is an indirect technique. All 3 cases of endometrial cancer were missed by Sonogram but picked up by hysteroscopy. [Table 6]. Sonogram diagnosed more endometrial polyps $(n=19)$ compared to hysteroscopy $(n=11)$ which makes it unreliable as only 8 cases were actual cases of endometrial polyps.

Sonogram detected only $60 \%$ of cases diagnosed as normal endometrium by hysteroscopy.

Endometrial polyps (18\%) and submucous myomas (12\%) detected by Sonogram were proved normal by hysteroscopy.

A considerable proportion of cases diagnosed as endometrial atrophy (30\%) by hysteroscopy were missed and wrongly branded as normal endometrium by Sonogram.

In all the diagnostic patterns, endometrial polyps were branded as diagnosis which showed the non-specificity of Sonogram in determining the type of mass lesion.

\begin{tabular}{|c|c|c|c|c|c|c|c|}
\hline \multirow{6}{*}{ Sonogram } & Total & 21 & 11 & 22 & 3 & 3 & 60 \\
\hline & $\begin{array}{l}\text { Endometrial } \\
\text { carcinoma }\end{array}$ & 0 & 0 & 0 & 0 & 0 & $\mathbf{0}$ \\
\hline & $\begin{array}{l}\text { Endometrial } \\
\text { atrophy }\end{array}$ & 0 & 0 & 0 & 2 & 0 & 2 \\
\hline & $\begin{array}{c}\begin{array}{c}\text { Sub-mucous } \\
\text { myoma }\end{array} \\
\end{array}$ & 3 & 0 & 12 & 0 & 3 & 18 \\
\hline & Endometrial polyp & 5 & 8 & 6 & 0 & 0 & 19 \\
\hline & \begin{tabular}{|c|} 
Normal \\
Endometrium \\
\end{tabular} & 13 & 3 & 4 & 1 & 0 & 21 \\
\hline & & $\begin{array}{c}\text { Normal } \\
\text { Endometrium }\end{array}$ & $\begin{array}{l}\text { Endometrial } \\
\text { polyp }\end{array}$ & $\begin{array}{c}\text { Sub- } \\
\text { mucous } \\
\text { myoma }\end{array}$ & $\begin{array}{l}\text { Endometrial } \\
\text { atrophy }\end{array}$ & $\begin{array}{l}\text { Endometrial } \\
\text { carcinoma }\end{array}$ & Total \\
\hline \multicolumn{8}{|c|}{\begin{tabular}{|c|} 
HYTEROSCOPY \\
\end{tabular}} \\
\hline \multicolumn{8}{|c|}{ Table 6. Sonogram versus Hysteroscopy } \\
\hline
\end{tabular}




\begin{tabular}{|c|c|c|c|c|c|c|c|}
\hline \multirow{6}{*}{ Histology } & Total & 21 & 11 & 22 & 3 & 3 & 60 \\
\hline & $\begin{array}{c}\text { Endometrial } \\
\text { carcinoma }\end{array}$ & 1 & 0 & 1 & 0 & 3 & 5 \\
\hline & $\begin{array}{l}\text { Endometrial } \\
\text { atrophy }\end{array}$ & 0 & 0 & 0 & 3 & 0 & 3 \\
\hline & \begin{tabular}{|c|}
$\begin{array}{c}\text { Sub-mucous } \\
\text { myoma }\end{array}$ \\
\end{tabular} & 0 & 0 & 19 & 0 & 0 & 19 \\
\hline & Endometrial polyp & 0 & 11 & 0 & 0 & 0 & 11 \\
\hline & $\begin{array}{c}\text { Normal } \\
\text { Endometrium } \\
\end{array}$ & 20 & 0 & 2 & 0 & 0 & 22 \\
\hline & & $\begin{array}{c}\text { Normal } \\
\text { Endometrium }\end{array}$ & $\begin{array}{l}\text { Endometrial } \\
\text { polyp }\end{array}$ & $\begin{array}{c}\text { Sub- } \\
\text { mucous } \\
\text { myoma }\end{array}$ & $\begin{array}{l}\text { Endometrial } \\
\text { atrophy }\end{array}$ & $\begin{array}{l}\text { Endometrial } \\
\text { carcinoma }\end{array}$ & Total \\
\hline
\end{tabular}

When hysteroscopy findings about the endometrium were subjected to histological verification based on endometrial biopsy, there was good concordance in diagnosis between the two diagnostic modalities. As seen above, the diagnosis by hysteroscopy missed only $10 \%$ cases of normal endometrium and detected them as submucous myoma. One case of endometrial cancer was diagnosed as benign myoma by hysteroscopy.

\begin{tabular}{|c|c|c|c|c|}
\hline & Hysteroscopy & Histology & Sensitivity & Specificity \\
\hline $\begin{array}{c}\text { Normal } \\
\text { Endometrium }\end{array}$ & 21 & 22 & $95.5 \%$ & $100 \%$ \\
\hline $\begin{array}{c}\text { Endometrial } \\
\text { polyp }\end{array}$ & 11 & 11 & $100 \%$ & $100 \%$ \\
\hline $\begin{array}{c}\text { Submucous } \\
\text { myoma }\end{array}$ & 22 & 19 & $100 \%$ & $92.7 \%$ \\
\hline $\begin{array}{c}\text { Endometrial } \\
\text { atrophy }\end{array}$ & 3 & 3 & $100 \%$ & $100 \%$ \\
\hline $\begin{array}{c}\text { Endometrial } \\
\text { carcinoma }\end{array}$ & 3 & 5 & $60 \%$ & $100 \%$ \\
\hline Overall & & & $94.7 \%$ & $86.4 \%$ \\
\hline \multicolumn{7}{|c|}{ Table 8. Sensitivity and Specificity of Hysteroscopy as } \\
\multicolumn{4}{|c|}{ Compared with Histology } \\
\hline
\end{tabular}

The sensitivity of hysteroscopy in detecting normal endometrium and endometrial carcinoma was lesser compared to the other diagnoses. Hysteroscopy lacked 100\% specificity in diagnosis of submucous myomas. Overall concordance was good between the hysteroscopic diagnosis and histology. Only 5\% ( 3 out of 60 cases) discordance was established between hysteroscopy and histology. This shows hysteroscopy as a reliable diagnostic method when compared with the gold standard diagnostic method namely endometrial biopsy.

\begin{tabular}{|c|c|c|}
\hline Type of Hyperplasia & Frequency & Percentage \\
\hline Simple without atypia & 33 & $55.0 \%$ \\
\hline Simple with atypia & 16 & $26.7 \%$ \\
\hline Complex without atypia & 1 & $1.7 \%$ \\
\hline Complex with atypia & 10 & $16.7 \%$ \\
\hline \multicolumn{2}{|c|}{ Table 9. Type of Endometrial Hyperplasia } \\
\hline
\end{tabular}

The endometrial pattern in majority showed simple hyperplasia without atypia.

Out of those cases ( $n=33), 12 \%$ were endometrial polyps and $27 \%$ were myomas. [Table 10]. Among those with simple hyperplasia with atypia, majority (43.7\%) were endometrial polyps by hysteroscopy followed by submucous myoma.
There were 10 cases of complex hyperplasia out of which hysteroscopy revealed two cases as endometrial cancer. Actual 3 cases branded as endometrial cancer by endometrial biopsy were histologically complex hyperplasias with atypia.

\begin{tabular}{|c|c|c|c|c|c|}
\hline \multirow[t]{2}{*}{ Hysteroscopy } & \multicolumn{4}{|c|}{ Hyperplasia type } & \multirow[b]{2}{*}{ Total } \\
\hline & $\begin{array}{c}\text { Simple } \\
\text { without } \\
\text { Atypia }\end{array}$ & $\begin{array}{c}\text { Simple } \\
\text { with } \\
\text { Atypia }\end{array}$ & $\begin{array}{c}\text { Complex } \\
\text { without } \\
\text { Atypia }\end{array}$ & $\begin{array}{c}\text { Complex } \\
\text { with } \\
\text { Atypia }\end{array}$ & \\
\hline $\begin{array}{c}\text { Normal } \\
\text { endometrium }\end{array}$ & 20 & 0 & 0 & 1 & 21 \\
\hline $\begin{array}{c}\text { Endometrial } \\
\text { polyp }\end{array}$ & 4 & 7 & 0 & 0 & 11 \\
\hline $\begin{array}{l}\text { Submucous } \\
\text { myoma }\end{array}$ & 9 & 6 & 0 & 7 & 22 \\
\hline End atrophy & 0 & 2 & 1 & 0 & 3 \\
\hline End cancer & 0 & 1 & 0 & 2 & 3 \\
\hline Total & 33 & 16 & 1 & 10 & 60 \\
\hline & & (1) & $\begin{array}{l}\text { ial Hyp } \\
\text { py }\end{array}$ & lasia and & \\
\hline
\end{tabular}

\section{Age-Related Endometrial Findings}

The occurrence of endometrial cavitary lesions varied with age as women in the age group of 31-40 years encountered more submucous myomas compared to the other age groups. The incidence of polyps increased with the age as seen as more polyps in the 41-50 years age group. Endometrial carcinoma found $80 \%$ incidence in the higher age category compared with the lower age groups. [Table 11].

\begin{tabular}{|c|c|c|c|c|}
\hline Hysteroscopy & \multicolumn{3}{|c|}{ Age Groups } & \\
\hline & $\begin{array}{l}20-30 \\
\text { Years }\end{array}$ & $\begin{array}{l}31-40 \\
\text { Years }\end{array}$ & $\begin{array}{l}41-50 \\
\text { Years }\end{array}$ & Total \\
\hline $\begin{array}{c}\text { Normal } \\
\text { endometrium }\end{array}$ & 7 & 15 & 0 & 22 \\
\hline $\begin{array}{l}\text { Endometrial } \\
\text { polyp }\end{array}$ & 0 & 7 & 4 & 11 \\
\hline $\begin{array}{c}\text { Submucous } \\
\text { myoma }\end{array}$ & 2 & 14 & 3 & 19 \\
\hline End atrophy & 0 & 2 & 1 & 3 \\
\hline End cancer & 0 & 1 & 4 & 5 \\
\hline Total & 9 & 39 & 12 & 60 \\
\hline
\end{tabular}

\section{DISCUSSION}

Abnormal uterine bleeding (AUB) is a common problem in any Gynaecology OPD. But the accuracy in detecting the underlying cause depends on various factors like availability of a proper diagnostic method, experience of the 
gynaecologist, cost, patients' co-operation, nature of the lesion, menopausal status, pregnancy-related complications, etc. Sensitivity, specificity, reliability, positive predictive value, negative predictive value and validity of the diagnostic tool determine how precise was the diagnosis made by the tool. Hysteroscopy has emerged as a reliable, sensitive and specific diagnostic method for abnormal uterine bleeding especially in precisely identifying the intrauterine pathology. Sonja Pop et al[8] in their study showed a very meagre failure rate of $2.09 \%$ for office hysteroscopy. In our study, the failure rate was zero. Hysteroscopy detected some pathology in 65\% $(n=39)$ of cases whereas it showed normal endometrium in the rest. In contrast, high percentage of abnormal hysteroscopic findings were evident in the study done by Lasmar et al[9] which documented that $80 \%$ of the hysteroscopies done detected some intrauterine lesions. In the above study, the age group of participants was higher (mean age $=45.5$ ) compared to the age group in our study (mean age $=36.85 \pm 5.6$ years). The hysteroscopy findings in the present study detected submucous myomas $(n=22$, $36.6 \%$ ) as a major common finding followed by normal endometrium $(n=21,35 \%)$ and endometrial polyps $(n=11$, 18.33\%). It detected 3 cases (5\%) as endometrial carcinoma.

In the study done by Shivalingaiah et al,[1] the detection of intrauterine pathologies by hysteroscopy was compared with the pickup of such lesions by trans-vaginal hysteroscopy. The study revealed that the pickup rate of polyps was $22.2 \%$ when compared to hysteroscopy. In the present study, the pickup rate of hysteroscopy was $100 \%$ in terms of polyps which again reconfirmed the efficacy of hysteroscopy.

The major ailments with which the patients presented in the OPD were menorrhagia $(40 \%, n=24)$, dysmenorrhoea $(25 \%, n=15)$, polymenorrhoea $(18.3 \%, n=11)$, metrorrhagia $(10 \%, n=6)$ and post-coital bleeding $(6.7 \%, n=6)$. [Table 14] The study done by Valson $\mathrm{H}$ et al[10] documented that there were no lesions documented as abnormal in the 21-30 years age group. The highest prevalence of intra-cavitary lesions was in the above 40 years age group (22\%). This was reverse in our study where in the prevalence of abnormality decreased with increasing age. The prevalence of endometrial cancer was highest $(100 \%)$ in the elder age groups.

The results of our study indicate a high sensitivity and specificity of hysteroscopy in detection of intrauterine pathology $(94.7 \%, 86.4 \%)$. Two cases which were diagnosed as normal and submucous myoma by hysteroscopy, turned out to be endometrial carcinoma by histopathology. Out of 22 cases detected as submucous myoma by hysteroscopy, two were declared normal endometrium and one as endometrial cancer by histopathology. When the above study by Valson $\mathrm{H}$ et al[10] results were compared with our study, the sensitivity was higher in our study compared to previous one (90.6\%) and specificity was lower than that study (96.4\%).

Most of the data available on the diagnostic accuracy of hysteroscopy in evaluation of abnormal uterine bleeding is relevant only for the post-menopausal patients unlike our study which includes pre-menopausal women also.[11,12] In the present study, the hysteroscopy findings in the 10 people, who were detected as complex hyperplasia of the endometrium with atypia by histology, revealed that 1 was branded as normal endometrium, 7 as submucous myomas and 2 as endometrial cancers. Hence, the risk of missing complex hyperplasia with atypia which can be a risk factor for carcinoma was high. But there was chance of missing one endometrial cancer case as normal endometrium by hysteroscopy. Arslan et al[13] performed diagnostic hysteroscopy in pre-menopausal (216 cases) and postmenopausal (114 cases) women for diagnosing endometrial hyperplasia. The positive predictive value and negative predictive value were $71.4 \%, 95.4 \%$ respectively in diagnosis. In the present study, the diagnostic accuracy was $87 \%$ as compared with the previous studies. In the present study, the pattern of bleeding was not much different between the premenopausal and post-menopausal women [Table 6]. Majority of the subjects (both pre-menopausal and post-menopausal women) had regular bleeding pattern which was heavy. Clinical Anaemia was detected in $30 \%(n=12)$ of the subjects and all of them presented with menorrhagia. In a prospective study done by Pal et al,[9] majority $(n=35)$ of the study participants had irregular heavy flow and few $(n=19)$ had regular flow. The study recorded an equal prevalence of intrauterine cavitary lesions between the patients with irregular heavy flow as well as those with regular bleeding pattern. In contrary, our study revealed more prevalence of intrauterine cavitary lesions among those with irregular bleeding patterns. In the present study, it was found that there was more regularity in bleeding among the postmenopausal women which questions the very fact of menopause. But all the post-menopausal patients were confirmed of absence of menstrual cycle for a considerable period before onset of abnormal bleeding by history. Hysteroscopy did not reveal much distinction in diagnostic efficacy between pre- and post-menopausal women. Study findings reassure that hysteroscopy cannot be an individual method for diagnosing the entire intrauterine lesion. But the study clearly documented that there was a good concordance of hysteroscopy with histopathology and it can diagnose better than ultrasonogram and other virtual diagnostic methods. The comparisons of results of this study with the previous studies showed new dimensions in the usage of hysteroscopy for diagnosing various lesions accurately especially the polyps and atrophies. It also alarmed the need of supportive histopathological evidence in diagnosis of endometrial hyperplasias and cancers.

\section{CONCLUSION}

The efficacy of hysteroscopy in correctly diagnosing the intrauterine pathology associated abnormal uterine bleeding among pre-menopausal and post-menopausal women was comparable to the diagnosis by histopathology. The sensitivity and specificity of hysteroscopy in diagnosing intrauterine pathology was high viz: $94.7 \%$ and $86.4 \%$.

Only in 5\% (3 out of 60) cases, discordance was established between hysteroscopy and histology. The major intrauterine lesions detected by hysteroscopy in patients with abnormal uterine bleeding were submucous myoma (36.7\%), endometrial polyp (18.3\%), endometrial atrophy (5\%) and endometrial carcinoma (5\%).

\section{ACKNOWLEDGEMENT}

I thank my professor, Dr. Hiremath. P. B who helped me in the work. 


\section{REFERENCES}

[1] Veena BT, Shivalingaiah N. Role of transvaginal sonography and diagnostic hysteroscopy in abnormal uterine bleeding. J Clin Diagn Res 2014;8(12):0C06-08.

[2] Sabherwal G, Sharnml B. Role of transvaginal sonography, diagnostic hysteroscopy and dilatation and curettage on cases of menorrhagia in the perimenopausal age group. J Obstet Gynec India 2002;55(3):106-08.

[3] Pal L, Lapensee L, Toth TL, et al. Comparison of office hysteroscopy, transvaginal ultrasonography and endometrial biopsy in evaluation of abnormal uterine bleeding. Journal of the Society of Laparoendoscopic Surgeons JSLS 1997;1(2):125-30.

[4] Gimpleson RJ. Panoramic hysteroscopy with directed biopsies versus dilatation and curettage for accurate diagnosis. J Reprod Med 1984;29(8):575-8.

[5] Gimpleson RJ, Rappold HO. A comparative study between panoramic hysteroscopy with directed biopsies and dilatation and curettage. A review of 276 cases. Am J Obstet Gynecol 1988;158(3 Pt 1):489-92.

[6] van Dongen H, de Kroon CD, Jacobi CE, et al. Diagnostic hysteroscopy in abnormal uterine bleeding: a systematic review and meta-analysis. BJOG 2007;114(6):664-75.

[7] Bradley H, Nezhat F. Hysteroscopy. In: Nezhat C. edr. Nezhat's operative gynecologic laparoscopy and hysteroscopy. New York: Cambridge University Press 2008:577-9.
[8] Pop-Trajkovic-Dinic S, Ljubic A, Kopitovic V, et al. The role of hysteroscopy in diagnosis and treatment of postmenopausal bleeding. Vojnosanitetski Pregled 2013;70(8):747-50.

[9] Lasmar RB, Dias R, Barrozo PR, et al. Prevalence of hysteroscopic findings and histologic diagnoses in patients with abnormal uterine bleeding. Fertility and Sterility 2008;89(6):1803-7.

[10] Valson H, Kulkarni C, Mukerjee S, et al. The role of diagnostic hysteroscopy in abnormal uterine bleeding and its histopathological correlation following blind dilatation and curettage. International Journal of Reproduction, Contraception, Obstetrics and Gynecology 2017;5(3):609-14.

[11] Granberg S, Wikland M, Karlsson B, et al. Endometrial thickness as measured by endovaginal ultrasonography for identifying endometrial abnormality. Am J Obstet Gynecol 1991;164(1 Pt 1):47-52.

[12] Goldstein SR, Nachtigall M, Snyder JR, et al. Endometrial assessment by vaginal ultrasonography before endometrial sampling in patients with post-menopausal bleeding. Am J Obstet Gynecol 1990;163(1 Pt 1):119-23.

[13] Arslan S, Aytan H, Gunyeli I, et al. Office hysteroscopic evaluation of endometrium. Can we hit the target? Arch Gynecol Obstet 2005;271(3):200-2. 